\title{
Shared Placenta
}

National Cancer Institute

\section{Source}

National Cancer Institute. Shared Placenta. NCI Thesaurus. Code C124582.

A condition found in some polyzygotic pregnancies where two or more fetuses share a single placenta. 